\title{
HISTÓRIA DA EDUCACÃO BRASILEIRA: A PRODUÇÃO CIENTÍFICA NA BIBLIOTECA ELETRÔNICA SCIELO
}

\author{
Maria Cristina Piumbato In nocentin. Hayash I* \\ Amarilio Ferreira Jr. ${ }^{* *}$ \\ M ARISA BITAR ${ }^{* * *}$ \\ Carlos Roberto M assao Hayash ${ }^{* * a+k}$ \\ M ÁrCIA RegIna da SILVA ${ }^{* * * *}$
}

RESU M 0: $\mathrm{N}$ a atualidade, as facilidades de acesso, produção e disseminação de informação têm provocado repercussões na comunidade científica e modificado as estruturas de produção e divulgação científicas. A ampliação dos espaços de produção de conhecimento sobre a pesquisa em educacão no país sugere a existência de um conjunto significativo de trabal hos que têm se preocupado em analisar e refletir sobre a produção científica da área. D essa perspectiva, a integração dos estudos de educação com os da ciência da informação se constitui em importante contribuição na tarefa de identificar, selecionar, coletar, sistematizar e estruturar sistemas de informação que ampliem o campo de estudos em educação. Este artigo relata pesquisa sobre a produção científica no campo da história da educação, constituída

* D outora em Educação e professora associada do D epartamento de Ciência da Informação e do Programa de Pós-Graduação em Educação da Universidade Federal de São Carlos (UFSCAR).E-mail: dmch@ufscar.br

* Doutor em História Social e professor associado do D epartamento de Educação e do Programa de Pós-Graduação em Educação da uFsCAR. E-mail: ferreira@ufscar.br

* D outora em H istória Social e professora associada do D epartamento de Educação da uFscAR. E-mail: bittar@ufscar.br

**** D outor em Educação e professor adjunto do D epartamento de Ciência da Informação e do Programa de Pós-Graduação em Educação da ufsCAR. E-mail: massao@ufscar.br

***** D outoranda em Educação no Programa de Pós-G raduação em Educação da uFscAR e bibliotecária na U niversidade de São Paulo (uSP, Ribeirão Preto). E-mail: marciaregina@usp.br

Educ. Soc., Campinas, vol. 29, n. 102, p. 181-211, jan./abr. 2008

Disponível em বhttp://www.cedes.unicamp.br> 
H istória da educação brasileira: a produção científica na biblioteca eletrônica sc IELO

de artigos científicos publicados em periódicos publicados na biblioteca el etrônica SCIELO.

Palavras-chave: Educação. H istória da educação. Produção científica. SCIELO.

The History OF BRAZILIAN EDUCATION:

SCIENTIFIC PRODUCTION AT SCIELO ELECTRONIC LIBRARY

ABST RACT : N owadays, easy access, production and dissemination of information has been bringing about some repercussion in the scientific community and changed the structures of scientific production and dissemination. Improved opportunities of knowledge production in educational research in the country suggest the existence of a significant set of works revealing efforts to analyze and reflect on scientific production in this field. In this perspective, the integration of educational studies with studies in the field of information science are an important contribution in the task of identifying, selecting, collecting, systematizing, and structuring information systems that can widen up the field of studies in education. This article reports a research on scientific production in the field of history of education, consisting of scientific articles published in periodicals catalogued at SCIELO.

Key words: Education. H istory of education. Scientific production. SCIELO.

Introdução

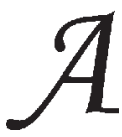

produção científica brasileira aumentou significativamente nestes últimos anos. A pesquisa científica da educação, em particular, apresenta um crescimento contínuo desde a década de 1960.

Em conferência de abertura do $V$ Encontro $N$ acional de Pesquisa em Educação em Ciências (v EN PEC), ocorrido em 2005, em Bauru/SP, $M$ arli $D$ almazo Afonso de André lembra que a pesquisa em educação no país não nasceu nas universidades. Segundo a pesquisadora, o começo da pesquisa foi induzido com a criação do INEP pelo MEC, para subsidiar a formulação de políticas públicas. André (2005) comenta que "em 1965, nós atingimos a maioridade forçada. De 1965 a 1975 foram abertos 16 cursos de pós-graduação na área. Aí a pesquisa se desloca do governo para a universidade. $\mathrm{H}$ oje, estamos rumo à maioridade, mas 40 anos ainda é 
pouco para a efetiva consolidação de massa crítica e um tempo curto para analisar e consertar erros nas pesquisas". A pesquisadora ainda comenta que nessas passagens houve mudanças: "O s temas se ampliaram e diversificaram, passaram da análise dos problemas externos nos anos 60 para o interno, o cotidiano da escola, a sala de aula, o currículo".

N o entanto, se a produção científica em educação não nasceu nas universidades, durante algum tempo ela se concentrou nos trabalhos de alguns professores vinculados às universidades brasileiras. 0 aumento desta produção se deve, principalmente, ao surgimento dos primeiros programas de pós-graduação em Educação, como 0 da puc-Rıo, em 1965, e o da puc-Sp, em 1969. Essa característica do aumento da produção científica via pós-graduação acontece também com a pesquisa científica brasileira em geral. O s cursos de pós-graduação são responsáveis por mais de $80 \%$ de toda produção científica brasileira (CAPES, 2006).

$\mathrm{N}$ o Brasil, o desenvolvimento da pesquisa está atrelado aos Planos $\mathrm{N}$ acionais de Pós-Graduação e às agências de fomento. No entanto, Gamboa (2003, p. 79) faz uma crítica ao modelo brasileiro de restrição da pesquisa à pós-graduação, uma vez que

\begin{abstract}
Atrelar a pesquisa à pós-graduação, além de "hierarquizar" os processos de produção do conhecimento no mestrado - onde se aprende, tardiamente, a pesquisar - e no doutorado - onde se aprimora o aprendizado e se obtém relativa autonomia para produzir conhecimento - também, alastra outros problemas como o da imposição de condições próprias dos rituais acadêmicos de obten ção de títul os e de progressão nas carrei ras docentes enquanto os protocolos da lógica da produção científica, na maioria dos casos, são depreciados.
\end{abstract}

0 autor acredita que associar a pesquisa somente à pós-graduação impossibilita que ela se inicie na graduação, o que sugere um início tardio das pesquisas, obrigando os pesquisadores a obterem os títulos necessários primeiramente, para só então começarem a pesquisar e a contribuir com a discussão e a resolução dos problemas latentes da sociedade.

$\mathrm{N}$ a atualidade, as facilidades de acesso, produção e disseminação de informação, aliadas a uma enorme quantidade de publicações eletrônicas, têm provocado repercussões na comunidade científica e modificado as estruturas de produção e divulgação científica. D esta perspectiva, pode-se verificar que foram ampliados os espaços de produção e divulgação de conhecimento em educação no país. Isso implica a existência de 
um conjunto significativo de trabal hos de pesquisa na área de educação que disponibilizam essa produção científica em diversos veículos de divulgação científica, inclusive na internet.

Ancorados na abordagem bibliométrica, realizamos um estudo sobre a produção científica concernente à história da educação disponível na biblioteca eletrônica SCIELO. O s estudos bibliométricos têm por objeto 0 tratamento e a análise quantitativa das publicações científicas; formam parte dos "estudos sociais da ciência" e entre suas principais aplicações se encontra a área de política científica.

Conforme Rostaing (1997), a bibliometria permite estabelecer re lações e análises a partir de contagens estatísticas de publicações ou de ele mentos extraídos dessas publicações e tem por objetivo medir as produções ("output") da pesquisa científica e tecnológica, por meio de dados originados não somente da literatura científica, mas também das patentes.

Esses estudos complementam, de maneira eficaz, as opiniões e os juízos emitidos pelos especialistas de cada área, proporcionando ferramentas úteis e objetivas nos processos de avaliação dos resultados da atividade científica. A bibliometria pode ser aplicada em campos diversos, entre eles: a) na história das ciências, para traçar a evolução das disciplinas; b) nas ciências sociais, para descobrir as motivações e as redes de pesquisadores; c) na documentação, para recenseamento de publicações científicas; d) na política científica, para fornecer indicadores de produtividade e de qualidade científica e tecnológica, tendo em vista a avaliação dos esforços em pesquisa e desenvolvimento.

$\mathrm{N}$ a visão de 0 kubo (1997), as abordagens bibliométricas que permitem descrever a ciência por meio de seus resultados repousam sobre a idéia de que o essencial da pesquisa científica é a produção de conhecimentos e que a literatura científica é a sua manifestação constitutiva.

\section{O cenário da pesquisa}

$\mathrm{N}$ o presente artigo, relatamos os resultados de uma pesquisa que objetivou analisar a produção científica no campo da história da educação disponível na base de dados SCIELO, visando verificar a sua contribuição para a consolidação dessa área de pesquisa no Brasil.

Segundo a categorização proposta por M arconi e Lakatos (1990) e C hizzotti (1991), a pesquisa realizada pode ser caracterizada como 
descritiva de caráter exploratório. A pesquisa também teve caráter documental por envolver leitura, sel eção e registro de literatura de interesse para o estudo proposto. É importante ressaltar que os dados coletados nesta pesquisa são de domínio público e o acesso a esses artigos científicos é gratuito.

A Scientific Electronic Library 0 n-Line (SCIELO) é uma biblioteca eletrônical desenvolvida em parceria entre a Fundação de Amparo à Pesquisa do Estado de São Paulo (FAPESP) e o Centro Latino-Americano e do Caribe de Informação em Ciências da Saúde (BIREM E). 0 projeto, iniciado em 1997 com o objetivo de disponibilizar eletronicamente as publicações científicas do Brasil e da América Latina, conta atualmente com 173 títulos de periódicos. A inclusão e permanência de uma revista no SCIELO segue critérios de qualidade que estão disponíveis em seu site na internet (Packer et al., 1998).

A metodologia Scıelo permite a publicação eletrônica de edições completas de periódicos científicos, a organização de bases de dados bibliográficas e de textos completos, a recuperação de textos por seu conteúdo, a preservação de arquivos el etrônicos e a produção de indicadores estatísticos de uso e impacto da literatura científica (Santos, 2005).

O ptamos pela scielo como fonte de pesquisa para este trabalho porque acreditamos que essa biblioteca eletrônica proporciona uma forma de garantir a visibilidade e a acessibilidade da literatura científica, além de espelhar a produção científica brasileira na internet.

\section{O scaminhos da pesquisa}

Para o desenvolvimento da pesquisa adotou-se uma metodologia nas seguintes etapas: 1) revisão de literatura sobre pesquisa em educação no Brasil, com foco na pesquisa em história da educação; 2) coleta de dados, no mês de março de 2006, na biblioteca eletrônica SCIELO; 3) descrição e categorização dos dados obtidos; 4) análise e interpretação dos resultados obtidos, realizadas à luz da abordagem bibliométrica e da teoria bourdieusiana de campo científico, com o objetivo de identificar as características dos artigos publicados.

Os dados obtidos foram analisados tendo em vista os seguintes aspectos: a) conhecer os autores cuja produção científica é referência na área; b) elucidar os temas gerais e específicos abordados nos artigos; 
c) identificar os periódicos nos quais os artigos foram publicados; d) ve rificar a distribuição geográfica e institucional dos autores; e) verificar o ano de publicação dos artigos; f) verificar os padrões de publicação dos autores que publicam artigos sobre história da educação.

\section{A produção científica em educação no Brasil}

H ayashi (2004) realizou uma reflexão histórica sobre a pesquisa em educação no Brasil e iniciou argumentando que não podemos deixar de considerar a existência de um conjunto de textos que, de acordo com Warde (1984), já se converteram em paradigmas, entre eles os produzidos por Gouveia (1970, 1974 e 1976) e C unha (1979), dedicados a descobrir as tendências da pesquisa em educação.

Warde (1990a) também realizou reflexões sobre o papel da pesquisa na pós-graduação em educação e sobre as contribuições da história para a educação (Warde, 1990b), assinalando que o crescimento quantitativo das pesquisas na área da educação "representa conquista de alto valor que deve ser imputada ao surgimento e à expansão dos cursos de pós-graduação na área" (Warde, 1990a, p. 68).

No início dos anos 2000, outras contribuições teórico-metodológicas para 0 crescimento da pesquisa em educação também foram objeto de estudo em um conjunto de trabalhos patrocinados pelo INEP e denominados "estado do conhecimento" (IN EP, 2006). As temáticas abordadas nesses estudos foram a alfabetização, a educação infantil, a formação de professores, a educação superior, as políticas e gestão da educação, a avaliação da educação básica, a juventude e escolarização e a educação de jovens e adultos no Brasil, os quais trouxeram importantes contribuições para a área.

Além dos estudos sobre "estados do conhecimento" na área de educação, outras iniciativas semelhantes têm sido realizadas no âmbito dos periódicos científicos. Entre essas cabe citar a mais recente, em 2004, promovida pela revista Educação \& Pesquisa, que organizou um fascículo especial dedicado inteiramente à publicação de artigos de revisão que apresentam balanços e análises críticas sobre temas relevantes da produção científica em educação, objetivando, segundo Carval ho e Bueno (2004, p. 8), "colaborar na organização da produção científica no campo educacional". 
Em relação à produção científica sobre história da educação, obje to de análise neste artigo, esta ganhou maior espaço a partir da década de 1980, com a criação da Associação N acional de Pós-Graduação e Pesquisa em Educação (AN PEd), em 1984, e do Grupo de Estudos e Pesquisas "H istória, Sociedade e Educação no Brasil" (HISTEDBR), em 1986. O bserva-se ainda que nos últimos anos tem havido maior interesse em estudos que se propõem a analisar a produção científica sobre a história da educação, os quais "têm buscado delinear um panorama da atual historiografia em educação, destacando temáticas e períodos privilegiados pela pesquisa, bem como aportes teóricos mais recorrentes nessa escrita disciplinar" (Vidal \& Faria Filho, 2003, p. 38).

Esta breve síntese da produção científica em educação no Brasil permite verificar que nos últimos anos se ampliaram os espaços de produção de conhecimento sobre a pesquisa em educação no país.

\section{A produção do conhecimento científico: um campo de disputas}

M uitas temáticas já foram analisadas nas pesquisas sobre história da educação e certamente contribuíram para a historiografia da educação, mas ainda existem muitos problemas da área que merecem ser investigados. Segundo Preveda (2004, p. 5),

A crise com que se depara a pesquisa educacional, quer na seleção de problemas para estudo, quer pela inadequação metodológica, quer pela fragmentação dos resultados, exige uma reorientação da pesquisa no caminho de uma "praxeologia educacional", onde teoria e prática andem interligadas, uma refletindo a outra no processo educacional.

No que se refere à produção científica, é importante mencionarmos que os pesquisadores em geral, não só os da área de educação, ainda sofrem a chamada "pressão" por publicação. Conforme Bourdieu (1983), os pesquisadores vivem em um lugar de lutas e associações, concorrências e acordos. Lutam por capital social e buscam o reconhecimento entre os pares por meio de crédito/credibilidade científica.

Ao conceber o campo científico tal um espaço social como outro qualquer, cheio de relações de força e disputas que visam beneficiar interesses específicos dos participantes desse campo, Bourdieu (1983) assinala que o "objeto de disputa" do campo científico é a posse exclusiva da 
autoridade científica. D este ponto de vista, a capacidade de "produzir ciência", por parte de um determinado indivíduo, está agregada a um determinado poder social. Para Bourdieu, nessa luta o que está em jogo é

(...) o monopólio da autoridade científica definida, de maneira inseparável, como capacidade técnica e poder social; ou, se quisermos, o monopólio da competência científica, compreendida como capacidade de falar e de agir legitimamente (isto é, de maneira autorizada e com autoridade), queésocialmente outorgada a um agente determinado. (Bourdieu, 1983, p. 122)

De acordo com a visão bourdieusiana, o campo científico é um lugar onde ocorre a concorrência na busca de vantagens e interesses específicos. O s pesquisadores estão vinculados a um determinado "campo científico", no qual exercem seu trabalho e suas escolhas científicas (teorias, metodologias etc.) e formam uma espécie de comunidade em que valores, crenças e práticas comuns são compartilhados. São elas que, de fato, orientam e representam sua posição política. Bourdieu (1983, p. 124) refere que estas práticas científicas estão orientadas pela "aquisição de autoridade científica". Considera ainda que o campo científico, como lugar de dominação e monopolização que acarreta luta por autoridade científica, é direcionado por estratégias políticas, de tal forma que:

N ão há "escolha" científica - do campo da pesquisa, dos métodos empregados, do lugar de publicação, ou, ainda, escolha entre uma publicação imediata de resultados parcial mente verificados e uma publicacão tardia de resultados plenamente controlados - que não seja uma estratégia política de investimento objetivamente orientada para a maximização do lucro propriamente científico, isto é, a obten ção do reconhecimento dos pares concorrentes. (Idem, ibid., p. 126)

Com base nesta visão, Bourdieu (1983) mostra que os cientistas, quando trocam novos conhecimentos, fazem-no utilizando um modelo que está fundado na noção de capital, de tal forma que o cientista acumula o chamado "crédito científico".

Assim, os recursos adquiridos pelos cientistas são os seus conhecimentos acumulados, os quais são utilizados em uma espécie de mercado, em troca do crédito científico. Por sua vez, esse crédito adquirido pode, posteriormente, ser reinvestido para conseguir mais crédito. Assinale-se, no entanto, que o conhecimento produzido pelo pesquisador é um bem que não possui muito valor em si mesmo. Ele precisa ser valorizado por 
outros produtores em sua troca e o reconhecimento que os outros Ihe dão é que dá a medida de sua importância. 0 autor considera que, "de fato, somente os cientistas engajados no mesmo jogo detêm os meios de se apropriar simbolicamente da obra científica e de avaliar seus méritos" (idem, ibid., p. 127).

Em síntese, a abordagem do campo científico realizada por Bourdieu (1983) mostrou que os conhecimentos novos produzidos pelas pesquisas se apóiam muito no pesquisador que os produz. Esses conhecimentos estão ligados com o interesse, o controle e a competição entre os próprios cientistas, para fins exclusivos de reconhecimento diante dos pares.

Com base nestes argumentos fica fácil compreender a existência de pressões para que os pesquisadores possam transmitir os resultados dos conhecimentos produzidos pelas pesquisas que realizam. Esta situação consolida a noção bourdieusiana de que a comunidade científica se assemelha a um sistema social em que seus membros almejam garantir a integridade e a aceitabilidade dos resultados por eles produzidos. Para que isso se concretize, é necessário que os pesquisadores utilizem os veículos de comunicação científica (publicações, apresentação de trabalhos em eventos etc.), para que suas informações alcancem seu público-alvo e se transformem em crédito científico.

Estas reflexões sobre a produção do conhecimento científico forneceram 0 arcabouço teórico, ao lado da abordagem bibliométrica, para analisar os principais achados da pesquisa realizada sobre a produção científica em história da educação publicada na biblioteca eletrônica SCIELO.

\section{O sprincipais achados da pesquisa}

Em um primeiro momento, foram recuperados 848 artigos na SCIELo, utilizando a expressão de busca "educação" e 437 artigos utilizando a expressão de busca "história". Para nos determos ao objetivo do trabalho, refinamos a pesquisa inicial utilizando como expressão de busca "história da educação". N essa etapa foram recuperados 24 artigos.

Buscando ampliar esse corpus, utilizamos outras expressões de busca. Por meio da opção de busca pelo assunto, lançamos o termo "história da educação" e 0 índice mostrou, além deste, uma lista de mais 99 termos de pesquisa iniciados por "história da...". 0 conjunto de artigos resultante 
dessa lista foi examinado para verificação sobre sua pertinência ou não à temática "história da educação", objeto da pesquisa aqui relatada. Esta estratégia nos remeteu aos termos "história da escola primária", "história do ensino primário", "história da educação e do trabalho", "história e educação". Com base no mesmo procedimento, utilizamos o termo "educação" e obtivemos mais 100 termos, os quais foram verificados e, entre eles, foi selecionada a expressão "educação jesuítica", por apresentar um artigo com temática pertinente ao tema pesquisado: "história da educação".

Portanto, estes cinco termos utilizados para pesquisa na base scielo resultaram em mais seis outros artigos relacionados à temática "história da educação", os quais foram acrescentados à lista inicial de 24 artigos. Assim, nosso corpus final para análise foi constituído de 30 artigos relacionados à temática "história da educação". Em seguida, todos estes artigos foram lidos integralmente visando a análises posteriores, de acordo com a metodologia adotada.

Como se configura a autoria dos artigos com temática em "história da educação"

A autoria das publicações científicas é um dado importante nos estudos de comunicação científica e está relacionada com a identificação dos pesquisadores e as instituições envolvidas, assim como seus países de origem. Como referem Balancieri et al. (2005), a relação de autoria é o conjunto de trabalhos cooperativos entre dois ou mais pesquisadores, identificados por meio de artigos, livros e capítulos de livros co-assinados.

$\mathrm{N}$ a pesquisa realizada os dados obtidos permitiram observar que, do total de 30 artigos recuperados na SCIELO, $26(86,7 \%)$ artigos têm autoria individual ao passo que $4(13,3 \%)$ são em co-autoria, representados por 3 artigos com 2 autores e 1 artigo com 3 autores, conforme mostra a tabela 1.

Estes achados confirmam os argumentos de Velho (1997a e 1997b), que assinala que alguns tipos de publicações predominam sobre outros. Segundo esta autora, os padrões de publicação variam de acordo com as áreas de conhecimento e na área de ciências humanas e sociais as publicações de autoria individual predominam, sendo observado um baixo nível de co-autorias. A prevalência da individualidade na autoria nessa área acontece, conforme assinala Silva (2004), em decorrência do fato de que 
nessa área "é preciso muito esforço para atingir concordância em várias decisões, tornando o processo muito difícil e o conflito iminente". Assim, a colaboração deixa de ser uma vantagem para o cientista. Ademais, como assinala Velho (1997a), o produto final dessas áreas tem um caráter ensaístico e individual, dificultando a concordância quanto ao conteúdo e no estilo. Infere-se destas argumentações que a colaboração não só é mais difícil em áreas nas quais os cientistas partilham o mesmo paradigma, mas também naquelas mais codificadas e literárias.

Tabela 1

( $N$ úmero de autores por artigo)

\begin{tabular}{|c|c|c|}
\hline N úmero de autores & N úmero de artigos & $\%$ \\
\hline 1 autor & 26 & 86,7 \\
2 autores & 3 & 10,0 \\
3 autores & 1 & 3,3 \\
\hline T otal & $\mathbf{3 0}$ & $\mathbf{1 0 0 , 0}$ \\
\hline
\end{tabular}

$\mathrm{N}$ a tabela 2 apresentamos os autores mais produtivos, considerando-se o número de artigos.

Tabela 2

(Autores mais produtivos por tipo de autoria)

\begin{tabular}{|l|c|c|}
\hline \multicolumn{1}{|c|}{ Autores } & Tipo de autoria & N úmero de artigos \\
\hline FARIA FILH O, Luciano & Individual & 2 \\
FARIA FILH O, Luciano & Co-autoria & 2 \\
PAU LILO, André Luis & Individual & 2 \\
ROCHA, H eloísa H. Pimenta & Individual & 2 \\
SAVIAN I, D ermeval & Individual & 3 \\
SOUZA, Rosa Fátima de & Individual & $\mathbf{1 3}$ \\
\hline \multicolumn{2}{|c|}{ Total } \\
\hline
\end{tabular}

Educ. Soc., Campinas, vol. 29, n. 102, p. 181-211, jan./abr. 2008 
A distribuição geográfica e institucional dos periódicos que publicam artigos sobre "história da educação"

O bservamos que há uma predominância dos periódicos pertencentes à região Sudeste. Esta característica se refletiu nos dados coletados neste trabalho, pois $96,7 \%$ (29) dos artigos recuperados foram publicados em periódicos do estado de São Paulo e apenas 1 $(3,3 \%)$ artigo no estado do Rio de Janeiro.

No estado de São Paulo, a distribuiçãa foi de 18 artigos (60\%) em periódicos publicados na cidade de São Paulo e 11 (36,7\%) artigos em periódicos publicados em Campinas (sP). Podemos observar melhor a distribuiçẫo destes dados na tabela 3.

Tabela 3

(D istribuição geográfica dos artigos publicados)

\begin{tabular}{|l|c|c|c|}
\hline Periódicos & O rigem geográfica & $\begin{array}{c}\text { Freqüência } \\
\text { absoluta }\end{array}$ & $\begin{array}{c}\text { Freqüência } \\
\text { relativa (\%) }\end{array}$ \\
\hline Educação e Pesquisa & São Paulo-SP & 6 & 20,0 \\
Cadernos de Pesquisa & São Paulo-SP & 4 & 13,3 \\
São Paulo em Perspectiva & São Paulo-SP & 3 & 10,0 \\
Revista Brasileira de H istória & São Paulo-SP & 3 & 10,0 \\
Revista da Faculdade de Educação & São Paulo-SP & 2 & 6,7 \\
\hline & Subtotal & $\mathbf{1 8}$ & $\mathbf{6 0 , 0}$ \\
\hline Cadernos CEDES & Campinas-SP & 6 & 20,0 \\
Educação \& Sociedade & Campinas-SP & 4 & 13,3 \\
Cadernos Pagu & Campinas-SP & 1 & 3,33 \\
\hline \multicolumn{1}{|c|}{ Subtotal } & $\mathbf{1 1}$ & $\mathbf{3 6 , 7}$ \\
\hline H istória, Ciências, Saúde- M anguinhos & Rio de Janeiro-RJ & 1 & 3,3 \\
\hline & Subtotal & $\mathbf{1}$ & $\mathbf{3 , 3}$ \\
\hline
\end{tabular}


A Tabela 3 também mostra que os periódicos Educação \& Pesquisa e CadernOS CEDES foram os que mais publicaram artigos com a temática "história da educação", com 6 artigos cada um, representando juntos $40 \%$ do total de 30 artigos pesquisados.

Com relação à origem institucional dos 9 periódicos publicados, verificou-se que 3 títulos são publicados por duas instituições ligadas à UN ICAM P (CEDEs e N úcleo de Estudos de Gênero - Pagu), com 11 artigos publicados (36,6\%), e 2 títulos são publicados pela Faculdade de Educação da USP, com 8 artigos publicados (26,7\%).

O s outros 5 títulos estão distribuídos entre dois tipos de instituições: 3 fundações (SEADE, Carlos Chagas e 0 swaldo C ruz) e uma associação (AN PUH), conforme dados da tabela 4.

O s dados da tabela 4 indicam que as instituições que publicam os periódicos, em sua maioria, estão ligadas ao meio acadêmico (universidades e núcleos de pesquisa), confirmando os achados de H ayashi (2004), Silva (2004) e Sacardo (2006), os quais apontaram que a divulgação do conhecimento científico no país se faz, principalmente, por meio de instituições acadêmicas.

\section{Tabela 4}

(O rigem institucional dos periódicos)

\begin{tabular}{|c|c|c|c|}
\hline Periódicos & Instituiç̧ão & Freqüência de artigos & $\begin{array}{l}\text { Freqüência } \\
\text { relativa (\%) }\end{array}$ \\
\hline $\begin{array}{l}\text { Cadernos CEDES } \\
\text { Educação \& Sociedade } \\
\text { Cadernos Pagu }\end{array}$ & $\begin{array}{l}\text { Centro de Estudos Educação e } \\
\text { Sociedade (CEDES - U N ICAM P) } \\
\text { N úcleo de Estudos de Gênero - } \\
\text { Pagu (UNICAM P) }\end{array}$ & $\begin{array}{l}6 \\
4 \\
1\end{array}$ & 36,6 \\
\hline $\begin{array}{l}\text { Educação e Pesquisa } \\
\text { Revista da Faculdade de Educação }\end{array}$ & $\begin{array}{l}\text { Faculdade de Educação da } \\
\text { U niversidade de São Paulo }\end{array}$ & $\begin{array}{l}6 \\
2\end{array}$ & 26,7 \\
\hline $\begin{array}{l}\text { Cadernos de Pesquisa } \\
\text { São Paulo em Perspectiva } \\
\text { H istória, Ciências, Saúde- } \\
\text { M anguinhos }\end{array}$ & $\begin{array}{l}\text { Fundação Carlos Chagas } \\
\text { Fundação SEADE } \\
\text { C asa de O swaldo Cruz - Fundação } \\
\text { O swaldo Cruz }\end{array}$ & $\begin{array}{l}4 \\
3 \\
1\end{array}$ & 26,7 \\
\hline Revista Brasileira de H istória & $\begin{array}{l}\text { Associação } \mathrm{N} \text { acional de } \mathrm{H} \text { istória - } \\
\text { AN PUH }\end{array}$ & 3 & 10,0 \\
\hline \multicolumn{2}{|l|}{ T otal } & 30 & 100,0 \\
\hline
\end{tabular}




\section{A origem institucional dos autores}

Q uando examinamos os autores dos 30 artigos, pode-se verificar que estes totalizam 26 e sua distribuição por instituição de vinculação pode ser observada na próxima tabela.

Tabela 5

(D istribuição das instituições de vinculação dos autores por tipo)

\begin{tabular}{|l|c|c|c|}
\hline \multicolumn{1}{|c|}{$\begin{array}{c}\text { Instituição } \\
\text { dos autores }\end{array}$} & $\begin{array}{c}\text { Tipo de } \\
\text { instituição (*) }\end{array}$ & $\begin{array}{c}\text { Freqüência } \\
\text { absoluta }\end{array}$ & $\begin{array}{c}\text { Frequiência } \\
\text { relativa (\%) }\end{array}$ \\
\hline USP & IES-P & 5 & 19,4 \\
UNICAMP & IES-P & 2 & 7,8 \\
UFSCAR & IFES & 2 & 7,8 \\
UFPR & IFES & 2 & 7,8 \\
UERJ & IES-P & 2 & 7,8 \\
UFMG & IFES & 1 & 3,8 \\
FUMEC-MG & IES-PR & 1 & 3,8 \\
USF & IES-CF & 1 & 3,8 \\
UMESP & IES-C & 1 & 3,8 \\
UGF-RJ & IES-PR & 1 & 3,8 \\
Universidade de Lisboa & IES-P & 1 & 3,8 \\
UNIMARCO & IES-PR & 1 & 3,8 \\
UNIRIO & IFES & 1 & 3,8 \\
UNESP/Araraquara & IES-P & 1 & 3,8 \\
UFSC & IFES & 1 & 3,8 \\
UFRGS & IFES & 1 & 3,8 \\
UFF & IFES & 1 & 3,8 \\
UFES & IFES & $\mathbf{1 0 0 , 0}$ \\
\hline Total & & 1 & 3,8 \\
\hline
\end{tabular}

(*): IEs-p: Instituição de Ensino Superior Pública; IEs-PR: Instituição de Ensino Superior Privada; IfEs: Instituiçãa Federal de Ensino Superior; IES-c: Instituição de Ensino Superior Confessional; IES-CF: Instituição de Ensino Superior Confessional Filantrópica. 
O s dados da Tabela 5 apontam que são 18 as instituições às quais os autores estão vinculados, de acordo com a seguinte distribuição: 8 (30,8 \%) são Instituições Federais de Ensino Superior (IfEs); 4 (15,4\%) são Instituições de Ensino Superior Públicas; 3 (11,5\%) são Instituições de Ensino Superior Privadas; 2 (7,7\%) são Instituições de Ensino Superior Confessionais, Comunitárias e Filantrópicas e 1 (3,8\%) é Instituição de Ensino Superior localizada no exterior (Portugal).

Verifica-se ainda que essas instituições se localizam em estados das regiões Sudeste (MG, ES, SP, RJ) e Sul (PR, SC e RS), confirmando assim OS dados da CAPES (2005), que indicam a maior concentração de cursos de pós-graduação nessas regiões do país.

\section{A participação dos autores em grupos de pesquisa}

Q uando confrontados com os dados disponíveis no D iretório de Grupos de Pesquisa no Brasil/cn pq, podemos verificar que 5 autores (Abreu Jr., M onteiro, N unes, Santos, Saviani) não participam ou os seus grupos de pesquisa não estão atualizados, ao passo que os 21 restantes $(80,7 \%)$ estão vinculados a 14 grupos de pesquisa, seja como líderes ou pesquisadores.

0 quadro 1 mostra os dados coletados na base corrente daquele Diretório, indicando a vinculação dos autores dos artigos em grupos de pesquisa, bem como os líderes desses grupos e as respectivas instituições a que pertencem.

O s dados do quadro 1 também mostram que al guns autores, tais como Vidal, Faria Filho, G ondra, Paulilo e Rocha, pertencem aos mesmos grupos de pesquisa, estabelecendo parcerias que formam uma rede de colaboração científica. Isso também é válido para outros autores, entre eles Bencostta e M arques; Boto e Carvalho; Faria e Gonçalves; Correia e Silva, Ferreira J r. e Bittar.

Retomamos aqui as considerações de Bourdieu (1983) sobre 0 fato de que o campo científico é um campo de lutas e disputas entre os pares, onde o que se busca é o crédito científico - trocado em um mercado no qual as publicações científicas têm importância fundamental, pois é por meio delas que os resultados das pesquisas (artigos científicos) alcançam seu público e se transformam em créditos que são trocados por outros. 
H istória da educação brasileira: a produção científica na biblioteca eletrônica scıelo

\section{Q uadro 1}

(Participação dos autores dos artigos em grupos de pesquisa cadastrados no D iretório de Grupos de Pesquisa no Brasil/cn pq)

\begin{tabular}{|c|c|c|c|}
\hline Autores & Grupos & Líderes & Instituição dos líderes \\
\hline $\begin{array}{l}\text { Vidal, D. } \\
\text { Faria Fo., L. } \\
\text { Gondra, J. } \\
\text { Paulilo, A. } \\
\text { Rocha, H. }\end{array}$ & $\begin{array}{l}\text { Educação, H istória e } \\
\text { M odernidade } \\
\text { N úcleo Interdisciplinar de } \\
\text { Estudos e Pesquisas em H istória } \\
\text { da Educação }\end{array}$ & $\begin{array}{l}\text { M aria Lúcia S. H ilsdorf } \\
\text { D iana Gonçalves }\end{array}$ & $\mathrm{FE} / \mathrm{USP}$ \\
\hline Gonçalves, I. A. & $\begin{array}{l}\text { Grupo de Estudos em H istória } \\
\text { da Educação }\end{array}$ & Luciano Faria Fo. & UFM G \\
\hline Oliven, $A$. & $\begin{array}{l}\text { Grupo de Estudos sobre } \\
\text { Universidade }\end{array}$ & Clarissa Baeta N eves & IFCH/UFRGS \\
\hline Schueler, A. & Crianças, Infâncias e Cultura & $\begin{array}{l}\text { Ana Cristina Coll } \\
\text { D elgado }\end{array}$ & FURG \\
\hline $\begin{array}{l}\text { Correia, A. } \\
\text { Silva, V. }\end{array}$ & $\begin{array}{l}\text { Arqueologia da Educação } \\
\text { M oderna }\end{array}$ & D enice Catani & FE/USP \\
\hline $\begin{array}{l}\text { Bencostta, } \mathrm{M} \text {. } \\
\text { M arques, } \mathrm{V} \text {. }\end{array}$ & H istória da Educação & M arcus L. Bencostta & UFPR \\
\hline $\begin{array}{l}\text { Boto, C. } \\
\text { Carvalho, M. M. C. }\end{array}$ & $\begin{array}{l}\text { Circulação e A propriação } \\
\text { de M odelos Pedagógicos no } \\
\text { Processo de Institucionalização } \\
\text { da Escola }\end{array}$ & $\begin{array}{l}\text { M arta M. C. de } \\
\text { Carvalho } \\
\text { M aria Lúcia S. H ilsdorf }\end{array}$ & $\mathrm{FE} / \mathrm{USP}$ \\
\hline D emartini, Z. & M igração, Cultura e Educação & Zeila D emartini & CERU \\
\hline Evangelista, 0 & $\begin{array}{l}\text { Políticas Educacionais e } \\
\text { Produção do Conhecimento }\end{array}$ & $\begin{array}{l}M \text { aria Célia } M \text { arcondes } \\
\text { de } M \text { oraes }\end{array}$ & UFSC \\
\hline G hiraldelli Jr., P. & $\begin{array}{l}\text { N úcleo de Pesquisa e Estudo- } \\
\text { Estado, Sociedade e Cidadania }\end{array}$ & W alderez M iguel & UCG \\
\hline Silva, C. & $\mathrm{H}$ istória da M atemática & Circe Silva da Silva & UFES \\
\hline Souza, R. F. & $\begin{array}{l}\text { Grupo de Estudos } \\
\text { Interdisciplinares sobre Cultura } \\
\text { e D esenvolvimento }\end{array}$ & Rosa F. de Souza & UNESP/Araraquara \\
\hline $\begin{array}{l}\text { Ferreira Jr., A. } \\
\text { Bittar, M. }\end{array}$ & Educação Jesuítica & Amarílio Ferreira Jr. & UFSCAR \\
\hline
\end{tabular}

Fonte: Diretório de Grupos de Pesquisa no Brasil/cn pq - Base corrente - coleta dos dados realizada em março de 2006. 
Podemos também adicionar a estes argumentos aquele apresentado por Price (1969), em sua obra Little science, big science, em que apontava que cientistas e pesquisadores tendem a se organizar em colégios inviśveis globais, compostos por pessoas que têm feito avançar as fronteiras do conhecimento.

No interior desses colégios, discussões, draft papers (rascunhos), conferências e trocas bilaterais de vários tipos provêm os membros com privilégios e acesso antecipado ao novo conhecimento. M embros desses colégios invisíveis estão engajados naquilo que tem sido chamado de "competição": uma mistura do comportamento cooperativo e competitivo. Colégi os invisíveis são, antes, negócios exclusivos. Aqueles que não podem levar nada de novo para a festa não estão convidados. Como todos os outros, eles podem ler revistas, mas são largamente excluídos nas trocas informais de técnicas, métodos e pistas sobre fracassos de pesquisas que são desfrutadas pelos membros do colégio invisível.

Estes argumentos de Bourdieu (1983) e Price (1969), somados aos dados empíricos da pesquisa realizada, levam-nos a supor que a produção científica em história da educação - pelo menos com relação aos resultados obtidos na presente pesquisa - está concentrada em alguns autores que pertencem a grupos de pesquisa e estabelecem parcerias científicas, as quais resultam em artigos científicos publicados. 0 u seja, poderíamos pensar que neste campo há determinados autores e grupos de pesquisa que são hegemônicos na produção do conhecimento da área.

Callon et al. (1993), ao se referirem ao ciclo de produção dos conhecimentos certificados, mencionam que é importante observar as seguintes etapas: a da produção e interpretação dos dados, a da publicação, a da interação e a do reconhecimento. Em relação ao reconhecimento, destacam que 0 autor que publica, e cujos artigos são considerados interessantes por seus pares, aumenta seu capital de credibilidade. Q uanto mais é reconhecido, mais fácil será obter financiamentos para sua pesquisa e atrair pesquisadores e técnicos, dando início a novo ciclo de produção de conhecimentos.

N este contexto da produção do conhecimento, lembramos aqui do estudo clássico de M erton (1973), The sociology of science, em que 0 autor introduziu o fenômeno conhecido como "efeito São M ateus" ( $M$ atthew Effect), em referência à passagem do Evangelho segundo São $M$ ateus que diz: "porque ao que tem se lhe dará mais e terá em abundância; mas ao que não tem, o pouco que tem Ihe será tirado". 
M erton (1973) referia-se ao fenômeno de que o êxito gera mais êxito. De acordo com o Efeito São $M$ ateus, de dois cientistas com igual quantidade de publicações (igual produtividade), o que trabal ha em uma universidade de mai or prestígio será mais reconhecido, ou reconhecido mais prontamente. Com esta teoria $\mathrm{M}$ erton queria assinalar que 0 sistema de recompensas influi na "estrutura de classe" da ciência, fornecendo uma distribuição estratificada de chances entre os cientistas ao ampliar seus papéis como pesquisadores. 0 processo provê acesso diferencial aos meios de produção científica (M erton, 1973). 0 sistema de comunicação da ciência também é afetado pelo Efeito São $M$ ateus, uma vez que uma contribuição inovadora terá maior visibilidade e aceitação quando for introduzida por um cientista de prestígio do que se for introduzida por um que ainda não se fez conhecer.

Como refere Garcia $(2005$, p. 9), a partir desta premissa M erton (1973) estudou "os sistemas de reconhecimento, comunicação e alocação de recursos e os efeitos de redundância decorrentes", o que nos leva a concordar com sua visão de que "na Academia o Evangelho de São M ateus é sumamente praticado" (idem, ibid., p. 9).

A produção científica sobre "história da educação" no período 1998-2005

Os dados obtidos na pesquisa também permitiram conhecer 0 crescimento das publicações sobre a temática "história da educação" presentes na SCIELO no período de 1998 a 2005, correspondentes à publicação dos 30 artigos pesquisados. A tabela 6 apresenta a distribuição desses artigos por ano de publicação.

Pelos dados obtidos observa-se que no período analisado se destacam os anos de 2000 com 10 artigos publicados (20\%) e 2004 com 6 artigos (20\%), totalizando 14 artigos $(53,3 \%)$. C ruzando-se estes dados com os títulos dos periódicos, verificamos que esses 14 artigos foram publicados em 6 periódicos, a saber: Cadernos CEDEs, Educação \& Sociedade, Educação \& Pesquisa, São Paulo em Perspectiva, Revista Brasileira de H istória e Cadernos de Pesquisa.

As possíveis explicações para estes resultados podem ser encontradas quando se analisam os números específicos dos periódicos que publicaram esses artigos. No caso da revista São Paulo em Perspectiva, verificamos 
que o volume 14, número 2, com 3 artigos publicados sobre "história da educação", foi uma edição temática dedicada à "Educação: cultura e sociedade" que se dispôs a discutir aspectos específicos e conjunturais da relação entre educação e sociedade.

Tabela 6

(D istribuição dos artigos por data de publicação)

\begin{tabular}{|c|c|c|}
\hline Ano de publicação & Freqüência absoluta & Freqüência relativa (\%) \\
\hline 1998 & 2 & 6,7 \\
1999 & 1 & 3,3 \\
2000 & 10 & 33,3 \\
2001 & 2 & 6,7 \\
2002 & 3 & 10,0 \\
2003 & 3 & 10,0 \\
2004 & 6 & 20,0 \\
2005 & 3 & 10,0 \\
\hline Total & $\mathbf{3 0}$ & $\mathbf{1 0 0 , 0}$ \\
\hline
\end{tabular}

I gualmente, o periódico Cadernos CEDES, que comparece com 6 artigos publicados no ano de 2000, sendo 1 artigo no volume 20, número 51 , e 5 artigos no volume 20 , número 52 . N o número 51 , na Apresentação da revista, Freitas e M onteiro $(2000$, p. 5) destacavam que

Por meio dos artigos organizados neste Cadernos CED ES, é nossa pretensão aprofundar a reflexão acerca da educação, da sociedade e da cultura no sé culo xıx, trabalhando temas que, no âmbito da H istória da Educação, façam emergir discursos e sociabilidades que se engendraram nesse período da $\mathrm{H}$ istória do Brasil. A elaboração destenúmero somente com artigos delimitados por uma abordagem temporal restrita ao século xıx traz uma preocupação em se recuperar eregistrar aspectos do nosso passado que permanecem atuais, delimitando discursos e práticas no campo educacional, a partir de um ideário liberal que se configurou na sociedade ena educação brasileira nesse período, forjando conceitos e uma forma de percepção social que sobrevivem além de seu próprio tempo. (G rifo nosso) 
Já o volume 52 - que compareceu com 1 artigo publicado entre os pesquisados sobre a temática "história da educação" - foi dedicado a discutir o tema "cultura escolar", conforme expresso na Apresentação assinada por Valdemarin e Souza (2000, p. 5):

D essa forma, o termo cultura escolar adquire uma significativa potencialidade explicativa e passa a se constituir em objeto de pesquisa e, de certa maneira, em uma abordagem aglutinadora, especialmente no campo da $\mathrm{H}$ istória da Educacão, no qual tem sido amplamente empregado, associado à reconceitualizaçã̃o do trabal ho histórico em educação. (G rifo nosso)

Verifica-se ainda que o restante dos artigos teve um crescimento gradativo, situado entre o mínimo de 1 e o máximo de 3 artigos produzidos nos anos de 1998, 1999, 2001-2003 e 2005.

\section{As temáticas dos artigos sobre "história de educação"}

A pesquisa realizada recuperou artigos na biblioteca eletrônica scielo com temática geral "história da educação". Para melhor analisar essas temáticas procedeu-se a uma avaliação das palavras-chave atribuídas nos respectivos artigos.

Foram identificadas 80 palavras-chave diferentes. $0 \mathrm{~s}$ artigos científicos recuperados possuem cada um no mínimo duas e no máximo cinco palavras-chave que identificam a sua temática, assim distribuídas: 1 $(3,3 \%)$ artigo possui duas palavras-chave, $36,7 \%$ (11 artigos) possuem três palavras-chave, $26,7 \%$ (8 artigos) possuem quatro palavras-chave e $33,3 \%$ (10 artigos) possuem cinco palavras-chave.

Como era esperado, a palavra-chave "história da educação" representou $28,6 \%$ (24 vezes) das palavras-chave utilizadas pelos autores. Isso aconteceu em razão da utilização desta expressão de busca para recuperar os artigos. Em seguida, com maior incidência apareceram as palavras-chave "cultura escolar" (4 vezes, representando $5 \%$ do total), "higiene" (3 vezes, representando 3,8\% do total) e as palavras-chave "Brasil", "educação", "história do currículo", "infância" e "práticas escolares" (2 vezes cada uma delas, representando 12,5\%). As outras 39 palavras-chave - do total de 80 palavras-chave encontradas - foram utilizadas uma vez cada, representando $48,8 \%$ do total.

Com base na pesquisa desenvolvida por Silva (2004), reunimos as palavras-chave em grupos temáticos. Para tanto, utilizamos um instrumento 
de indexação e recuperação de informações, desenvolvido pelo INEP/MEC, 0 Thesaurus Brased, vocabulário controlado na área de educação.

A justificativa para a sua utilização reside no fato de que nos vocabulários controlados estão os grandes temas de determinadas áreas do conhecimento e seus respectivos subtemas agrupados. Com base no Thesaurus Brased agrupamos por temas as 80 palavras-chave obtidas na pesquisa realizada na base de dados scielo. Excluímos dois termos ("japoneses em São Paulo" e "matemática") por não guardarem relação direta com a temática da educação. $\mathrm{N}$ a próxima tabela podemos visualizar o resultado do agrupamento destas palavras-chave, distribuídas em 21 temas.

O s dados da tabela 7 demonstram que o tema mais pesquisado é "história da educação", pois 20,5\% dos autores elegeram esta palavrachave como a mais representativa do assunto abordado em seus artigos. Em seguida, os temas que receberam maior número de palavras-chave foram, respectivamente, "educação escolar", com 12,9\%; "fundamentos da educação", com 11,5\%; "filosofia da educação", com 7,7\%; e "contexto humano", "instituições de ensino", "educação e lugares" e "publicações", com 5,1\% cada. Estes 8 temas totalizam 73\% das palavras-chave. Os demais 13 temas totalizaram $27 \%$ e tiveram entre quatro e uma palavras-chave atribuídas.

Ao analisar os dados obtidos do agrupamento das palavras-chave por temas, devemos ter o cuidado de considerar que, se a temática "história da educação" é majoritária entre os 21 temas (20,5\%), isso se deve à metodologia adotada para a pesquisa, que el egeu este termo para a busca dos artigos na base de dados scielo. Pode-se concluir, portanto, que esta escolha foi acertada tendo em vista os resultados obtidos.

D e acordo com a matriz conceitual do Thesaurus Brased, os dados da Tabela 7 indicam que $56,7 \%$ dos temas pesquisados se referem ao campo da "educação", ao passo que $21,7 \%$ dos temas se enquadram no campo de "fundamentos da educação", seguidos de $11,4 \%$ ao campo "escola" e 5,1\% ao campo "contexto da educação". O s restantes 5,1\% dos temas referem-se ao campo "identificadores e especificadores da informação", que classifica e complementa as informações relacionadas aos outros quatro campos.

Assim, o tema "história da educação", como subárea da "educação" inserida no campo "fundamentos da educação" no Thesaurus Brased, não é o mais representativo entre os artigos pesquisados, pois participa com 
H istória da educação brasileira: a produção científica na biblioteca eletrônica scıelo

$21,5 \%$ do total de temas. Este achado confirma aquele resultante das palavras-chave, entre as quais "história da educação" recebeu 20,5\% de atribuições do total dos artigos pesquisados.

Tabela 7

(Agrupamento das palavras-chave por temas, segundo os termos do Thesaurus Brased)

\begin{tabular}{|c|c|c|c|}
\hline Termos/T emas & Campos do Thesaurus B rased & Freqüência absoluta & $\begin{array}{l}\text { Freqüência relativa } \\
\qquad(\%)\end{array}$ \\
\hline H istória da educação & \multirow[t]{7}{*}{ Educação } & 16 & 20,5 \\
\hline Educação escolar & & 10 & 12,9 \\
\hline Filosofia da educação & & 6 & 7,7 \\
\hline Educação & & 4 & 5,1 \\
\hline Currículo & & 3 & 3,9 \\
\hline M aterial didático & & 3 & 3,9 \\
\hline $\begin{array}{l}\text { Processo de ensino- } \\
\text { aprendizagem }\end{array}$ & & 2 & 2,7 \\
\hline Instituições de ensino & \multirow[t]{5}{*}{ Escola } & 4 & 5,1 \\
\hline Política da educação & & 2 & 2,7 \\
\hline Pesquisa da educação & & 1 & 1,2 \\
\hline Administração escolar & & 1 & 1,2 \\
\hline Economia da educação & & 1 & 1,2 \\
\hline Fundamentos da educação & \multirow[t]{7}{*}{ Fundamentos da educação } & 9 & 11,5 \\
\hline Comunicação e educação & & 2 & 2,7 \\
\hline Saúde e educação & & 2 & 2,7 \\
\hline Filosofia e educação & & 1 & 1,2 \\
\hline Trabalho e educação & & 1 & 1,2 \\
\hline Psicologia e educação & & 1 & 1,2 \\
\hline Sociologia e educação & & 1 & 1,2 \\
\hline Contexto humano & Contexto da educação & 4 & 5,1 \\
\hline Lugares e publicações & $\begin{array}{c}\text { Identificadores e } \\
\text { especificadores de informação }\end{array}$ & 4 & 5,1 \\
\hline \multicolumn{2}{|l|}{ T otal } & 78 & 100,0 \\
\hline
\end{tabular}

Fonte: INEP/MEC - Thesaurus Brased. 
É necessário lembrar, entretanto, que o objeto de estudo da presente pesquisa foram os artigos publicados na base de dados SCIELO. Isso nos obriga a considerar que a produção científica em história da educação inclui outros tipos de trabalhos além dos artigos, entre eles as teses e dissertações produzidas pelos programas de pós-graduação do país, os livros e capítulos de livros e os trabalhos científicos apresentados em eventos, o que aponta para a ampliação do campo. Em pesquisa sobre 0 estado da arte em história da educação após 1985, Bittar (2006, p. 11) menciona que

(...) diversos caminhos poderiam ser trilhados para compor o estado da arte em H istória da E ducação sobre o período após 1985. Talvez o mais seguro fosse 0 arrolamento de todos os livros, teses e dissertações publicadas sobre o período. Q uanto aos livros, possivelmente déssemos conta de arrolar a produção da área, mas o mesmo não poderíamos afirmar em relação às dissertações e teses, considerando o seu atual volume.

Bittar (2006) também menciona que a própria constituição do campo da história da educação, a partir do final da ditadura militar, ganhou maior amplitude e complexidade, assinalando a constituição de entidades representativas na área, as quais, como 0 "GT/AN PEd em H istória da Educação (1984); a criação do HISTED BR (1986) e, por fim, a fundação da Sociedade Brasileira de H istória da Educação - SBHE - (1999), se tornaram um canal sistemático de veiculação da produção realizada na área, além de suscitar novas pesquisas" (p. 12).

\section{Consideraçõesfinais}

O s resultados obtidos em pesquisa realizada em periódicos da biblioteca eletrônica SCIELO e descritos neste artigo sugerem que a história da educação brasileira ainda é um campo pouco pesquisado na área de educação. Sua inserção nos periódicos da área, representada por artigos elaborados por pesquisadores que estão vinculados a diferentes instituições científicas e grupos de pesquisa do país, ainda é incipiente, haja vista que os 30 artigos pesquisados estão distribuídos em 9 periódicos.

Também podemos considerar que a produção científica neste campo da história da educação se mostra hegemônica em termos dos autores que publicam artigos nessa área, pois muitos deles estão vinculados aos mesmos grupos de pesquisa. 
O s dados da pesquisa ainda parecem evidenciar que, além de formarem uma rede de colaboração científica - ou, nos termos de Bourdieu, por causa dessas redes de colaboração científica -, esses pesquisadores também são majoritários em termos de publicação de artigos relacionados à temática "história da educação" nos periódicos científicos. N este contexto, também cabe reconhecer, como o fizeram Lopes e Piscitelli (2004, p. 120), que "a lógica que incide na organização dos campos de estudo afeta as publicações acadêmicas".

Finalmente, gostaríamos de registrar que os achados da pesquisa relatados neste artigo não permitem generalizações que extrapolem 0 universo da pesquisa - somente em periódicos na SCIELO -, pois ainda precisam ser aprofundados em termos das análises e constituem uma primeira aproximação ao campo da produção científica sobre a "história da educação".

Recebido em janeiro de 2007 e aprovado em dezembro de 2007.

\section{N otas}

1. Várias são as definições que têm sido dadas às bibliotecas eletrônicas. N este artigo consideramos biblioteca eletrônica aquela que permite acessar bancos de dados em formato eletrônico (base de dados on-line).

2. D e acordo com a SESU/MEC, as instituições de ensino superior brasileiras estão organizadas em duas categorias administrativas: as públicas e as privadas. .As instituições privadas podem se organizar como "instituições com fins lucrativos ou particulares em sentido estrito" e "instituições privadas sem fins lucrativos". Estas últimas podem ser: comunitárias (instituídas por grupos de pessoas físicas ou por uma ou mais pessoas jurídicas, inclusive cooperativas de professores e alunos, que incluam representantes da comunidade na sua entidade mantenedora), confessionais (instituídas por grupos de pessoas físicas ou por uma ou mais pessoas jurídicas que atendam à orientação confessional e ideológica, específicas) e filantrópicas (são as instituições de educação ou de assistência social que prestem os serviços para os quais foram instituídas e os coloquem à disposição da população em geral, em caráter complementar às atividades do Estado, sem qualquer remuneração). N o site da SESU/ MEC podem ser realizadas buscas para verificar o tipo de instituição.

\section{Referências}

AN D RÉ, M .E.D.A. Pesquisa em educação: questões de teoria e método. In: ENCONTRO NACIONAL DE PESQUISA EM EDUCAÇÃO E CIÊN CIAS, 5., 2005, Bauru. Anais.. São Paulo: ABRAPEC, 2005. 
BALAN CIERI, R. et al. A análise de redes de colaboração científica sob as novas tecnologias de informação e comunicação: um estudo na Plataforma Lattes. Ci ência da Informação, Brasília, DF, v. 34, n. 1, p. 6477, jan./abr. 2005.

BITTAR, M . 0 estado da arte em história da educação brasileira após 1985: um campo em disputa. In: Lom BARDI, J.C.; SAVIANI, D.; N Ascim ENTO, M I. .M. (O rg.). N avegando pela história da educação. Campinas: HISTED BR, 2006. p. 1-24. Disponível em: «ttp://www.histebr.fae.unicamp.br/navegando/ index.html>. Acesso em: nov. 2006.

BOURDIEU, P. O campo científico. In: OrTIz, R. (0 rg.). Pierre Bourdieu: sociologia. São Paulo: Ática, 1983. cap. 4, p. 122-155. (Grandes cientistas sociais, 39)

BRASIL. M inistério da Educação. Instituto N acional de Estudos e Pesquisas Educacionais (IN EP). D isponível em: 〈http://www.inep.gov.br/>. Acesso em: mar. 2006.

BRASIL. M inistério da Educação. Instituto N acional de Estudos e Pesquisas Educacionais (IN EP). T hesaurus Brased. D isponível em: বttp:// www.inep.gov.br/pesquisa/thesaurus/ >. Acesso em: mar. 2006.

BRASI L. M inistério da Educação. Secretaria de Educação Superior (sESU). Tipos de instituição. D isponível em: 〈tttp://www. educacaosuperior.inep.gov.br/ tipos_de_instituicao.stm>Acesso em: mar. 2006.

CALLON, M. et al. La scientométrie. Paris: PUf, 1993.

CARVALH O, M .P.; BU EN O , B.O . Editorial. Educação \& Pesquisa, São Paulo, v. 30, n. 1, p. 7-8, jan./abr. 2004.

CHIZZOTTI, A. Pesquisa em ciências humanas e sociais. São Paulo: Cortez, 1991.

COORDENAÇÃO DE APERFEIÇOAMENTO DE PESSOAL DE NIVEL SU PERIOR (CAPES). Relação de cursos recomendados e reconhecidos. Brasília, DF: CAPES/M EC, 2005. D isponível em: «ttp://www1.capes.gov.br/ Scripts/Avaliacao/M eD oReconhecidos/Regiao/Regiao.asp>. Acesso em: fev. 2006. 
COORDENAÇÃO DE APERFEIÇOAMENTO DE PESSOAL DE NIVEL SU PERIOR (CAPES). Estatísticas da pósgraduação. D isponível em: বttp://www.capes.gov.br/capes/portal/conteudo/10/EstatisticasPG .htm>. Acesso em: fev. 2006.

CUNHA, L.A. O s (des)caminhos da pesquisa na pós-graduação em educação. In: SEM IN ÁRIO SOBRE A PRODUÇÃO CIENTIIFICA NOS PRO GRAM AS DE PÓS-GRADUAÇÃO EM EDUCAÇÃO. Anais... Braślia, DF: MEC/CAPES, 1979. p. 3-15.

DUARTE, S.G. Dicionário brasileiro de educação. Rio de Janeiro: Antares; Nobel, 1986. 175p.

FREITAS, A.G.B.; M ON TEIRO, R.M. Apresentação. Cadernos CED ES, Campinas, v. 20, n. 51, p. 5-7, nov. 2000.

GAM BOA, S.S. As condições da produção científica em educação: do modelo de áreas de concentração aos desafios das linhas de pesquisa. Educação Temática Digital, Campinas, v. 4, n. 2, p. 78-93, jun. 2003.

GARCIA, J.C.R. 0 efeito M atheus. Jornal da ADUfPB, João Pessoa, n. 100, p. 9, jul. 2005.

GOUVEIA, A.J. A pesquisa educacional no Brasil. Cadernos de Pesquisa, São Paulo, v. 1, p. 1-20, jul. 1970.

GOUVEIA, A.J. Algumas reflexões sobre a pesquisa educacional no Brasil. Revista Brasileera de Estudos Pedagógicos, Brasília, DF, v. 60, n. 135, p. 495-500, out./dez. 1974.

GOUVEIA, A.J. A pesquisa sobre educação no Brasil: de 1970 para cá. Cadernos de Pesquisa, São Paulo, v. 19, p. 75-79, dez. 1976.

HAYASH I, C.R.M. Presença da educação brasileira na base de dados Francis: uma abordagem bibliométrica. 2004. D issertação (M estrado em Educação) - Programa de Pós-Graduação em Educação, U niversidade Fe deral de São Carlos, São Carlos.

LOPES, M . M .; PISCITELLI, A. Revistas científicas e a constituição do campo de estudos de gênero: um olhar desde "as margens". Revista de Estudos Feministas, Florianópolis, v. 12, n. esp., p. 115-121, set./dez. 2004. 
M aria Cristina Piumbato Innocentini H ayashi et al.

MARCONI, M.A.; LAKATOS, E.M. Técnicas de pesquisa. São Paulo: Atlas, 1990.

MERTON, R.K. The sociology of science: theoretical and empirical investigation. Chicago: University of Chicago, 1973. cap. 20, p. 439-459.

OKUBO, Y. Indicateurs bi bliométriques et analyse des systemes de recherche: méthodes et exemples. Paris: OCDE, 1997. (D ocuments de travail de la DSTI, 41)

PACKER, A.L. et al. SCIELo: uma metodologia para publicação eletrônica. Ciência da Informação, Braślia, DF, v. 27, n. 2, p. 109-121, 1998.

PREVEDA, N.J. Pesquisa em educação: mudança de paradigma? Re vista Virtual: Contestado e Educação, Contestado, v. 7, mar. 2004. Disponível em: বhttp://www.pg.cdr.unc.br/RevistaV irtual/N umeroSete/ RevistaV irtual.htm>. Acesso em: mar. 2006.

PRICE, D.S. Little science, big science. N ova York: Columbia University, 1969.

RO ST AIN G, H . La bibliométrie et ses techniques. Toulouse: Sciences de la Société; M arseille: Centre de Recherche Rétrospective de $M$ arseille, 1997.

SACARD O , M .S. Publicação científica derivada de dissertações e teses na interface entre a Educação Física e a Educação Especial. 2006. D issertação (M estrado em Educação Especial) - Programa de Pós-Graduação em Educação Especial, U niversidade Federal de São Carlos, São Carlos.

SANTOS, S. M etodologia SCIELO de publicação eletrônica. In: REU N IÃO DE COORDEN AÇÃO REGION AL DA BVS, 4., 2005, Salvador. Disponível em: বhttp://bvs4.icml9.org/gt/eport/>. Acesso em: jan. 2006.

SCIELO. Scientific Electronic Library O nline. Disponível em: «ttp:// www.scielo.br/scielo.php/script_sci_home/lng_pt/nrm_iso> Acesso em: mar. 2006.

SI LVA, M .R. Análise bibliométrica da produção científica docente do Programa de PósG raduação em Educação Especial/u FsCAR. 2004. D issertação (M estrado em Educação Especial) - Universidade Federal de São Carlos, São Carlos. 
VALDEM ARIN, V.T.; SO UZA, R.F. Apresentação. Cadernos CEDES, Campinas, v. 20, n. 52, p. 5-9, nov. 2000.

VELH O, L. N otas sobre a pós-graduação em Ciências Sociais e humanidades: por que e em quê diferem das ciências naturais? Brasília, DF: UNESCO, $1997 a$.

VELH O, L. A ciência e seu público. Transinformação, Campinas, v. 9, n. 3, set./dez. 1997b.

VIDAL, D.G.; FARIA FILH O, L.M. H istória da educação no Brasil: a constituição histórica do campo (1880-1970). Revista Brasileira de H is tória, São Paulo, v. 23, n. 45, p. 37-70, jul. 2003.

WARDE, M .J. Anotações para uma historiografia da educação brasileira. Em Aberto, Brasília, DF, v. 3, n. 23, p. 1-6, set./out. 1984.

WARDE, M .J. Contribuições da história para a educação. Em Aberto, Brasília, DF, v. 9, n. 47, p. 3-11, jul./set. 1990a.

WARDE, M.J. 0 papel da pesquisa na pós-graduação em educação. Cadernos de Pesquisa, São Paulo, n. 73, p. 57-75, 1990b.

\section{Artigos pesquisados na biblioteca sc IELO}

ABREU JUNIOR, L.M . O caderno de recortes sobre educação do "Diario Official do Estado de São Paulo": indícios de cultura material na escola primária "D r. Jorge Tibiriçá" (1930-1947). Revista Brasileira de História, São Paulo, v. 24, n. 48, p.171-188, 2004.

BEN COSTTA, M.LA. Cultura escolar e história eclesiástica: reflexões sobre a ação romanizadora pedagógica na formação de sacerdotes católicos e o Seminário Diocesano de Santa M aria (1915-1919). Cadernos CEDES, Campinas, v. 20, n. 52, p. 88-103, nov. 2000.

BO TO , C. Aprender a ler entre cartilhas: civilidade, civilização e civismo pelas lentes do livro didático. Educação \& Pesquisa, São Paulo, v. 30, n. 3, p. 493-511, set./dez. 2004.

CARVALH O, M .M.C. M odernidade pedagógica e modelos de formação docente. São Paulo em Perspectiva, São Paulo, v. 14, n. 1, p. 111-120, jan./mar. 2000. 
DEM ART IN I, Z.B.F. Relatos orais de famílias de imigrantes japoneses: elementos para a história da educação brasileira. Educação \& Sociedade, Campinas, v. 21, n. 72, p. 43-72, ago. 2000.

EVAN GELISTA, 0 . Formar o mestre na universidade: a experiência paulista nos anos de 1930. Educação \& Pesquisa, São Paulo, v. 27, n. 2, p. 247-259, jul./dez. 2001.

FARIA FILH O, L.M . O espaço escolar como objeto da história da educação: algumas reflexões. Revista da Faculdade de Educação, São Paulo, v. 24, n. 1, p. 141-159, jan./jun. 1998.

FARIA FILH O, L.M . Para entender a relação escola-família: uma contribuição da história da educação. São Paulo em Perspectiva, São Paulo, v. 14, n. 2, p. 44-50, abr./jun. 2000.

FARIA FILHO, L.M.; GON ÇALVES, I.A.; VIDAL, D.G. A cultura escolar como categoria de análise e como campo de investigação na história da educação brasileira. Educação \& Pesquisa, São Paulo, v. 30, n. 1, p. 139-159, jan./abr. 2004.

FERREIRA JU N IOR, A.; BITTAR, M. Pluralidade lingüística, escola de bêá-bá e teatro jesuítico no Brasil do século xvı. Educação \& Sociedade, Campinas, v. 25, n. 86, p. 171-195, abr. 2004.

GHIRALDELLI JUNIOR, P. A teoria educacional no 0 cidente: entre modernidade e pós-modernidade. São Paulo em Perspectiva, São Paulo, v. 14, n. 2, p. 32-36, abr./jun. 2000.

GONDRA, J.G. A sementeira do porvir: higiene e infância no século XIX. Educação \& Pesquisa, São Paulo, v. 26, n. 1, p. 99-117, jan./jun. 2000.

M ARQUES, V.R.B. H istórias de higienização pelo trabalho: crianças paranaenses no novecentos. Cadernos CEDES, Campinas, v. 23, n. 59, p. 57-78, abr. 2003.

M O NTEIRO, R.M. Civilização e cultura: paradigmas da nacionalidade. Cadernos Cedes, Campinas, v. 20, n. 51, p. 50-65, nov. 2000.

N U NES, C. H istoriografia comparada da escola nova: algumas questões. Revista da Faculdade de Educação, São Paulo, v. 24, n. 1, p. 105-125, jan./ jun. 1998. 
OLIVEN, A.C. A marca de origem: comparando colleges norte-americanos e faculdades brasileiras. Cadernos de Pesquisa, São Paulo, v. 35, n. 125, p. 111-135, maio/ago. 2005.

PAU LILO , A.L. Aspectos políticos das reformas da instrução pública na cidade do Rio de Janeiro durante os anos 1920. Revista Brasileira de $\mathrm{H}$ is tória, São Paulo, v. 23, n. 46, p. 93-122, 2003.

PAU LILO , A.L. Projeto político e sistematização do ensino público brasileiro no século xıx. Cadernos de Pesquisa, São Paulo, v. 34, n. 122, p. 467-496, maio/ago. 2004.

RO CH A, H .H .P. A educação sanitária como profissão feminina. Cadernos Pagu, Campinas, n. 24, p. 69-104, jan./jun. 2005.

ROCH A, H .H .P. Prescrevendo regras de bem viver: cultura escolar e racionalidade científica. Cadernos CEDES, Campinas, v. 20, n. 52, p. 5573, nov. 2000.

SAN TOS, J.J.M. H istória do lugar: um método de ensino e pesquisa para as escolas de nível médio e fundamental. H istória, Ciências, Saúde M anguinhos, Rio de Janeiro, v. 9, n. 1, p. 105-124, jan./abr. 2002.

SAVIAN I, D. C asemiro dos Reis Filho e a educação brasileira. Educação \& Sociedade, Campinas, v. 22, n. 77, p. 161-181, dez. 2001.

SAVIAN I, D. Percorrendo caminhos na educação. Educação \& Sociedade, Campinas, v. 23, n. 81, p. 273-290, dez. 2002.

SCH U ELLER, A.F. Representações da docência na imprensa pedagógica na Corte imperial (1870-1889): 0 exemplo da Instrução Pública. Educação \& Pesquisa, São Paulo, v. 31, n. 3, p. 379-390, set./dez. 2005.

SILVA, C.M .S. Formação de professores e pesquisadores de matemática na faculdade nacional de filosofia. Cadernos de Pesquisa, São Paulo, n. 117, p. 103-126, nov. 2002.

SILVA, V.B.; CORREIA, A.C.L. Saberes em viagem nos manuais pedagógicos (Portugal - Brasil). Cadernos de Pesquisa, São Paulo, v. 34, n. 123, p. 613-632, set./dez. 2004.

SO UZA, R.F. A militarização da infância: expressões do nacionalismo na cultura brasileira. Cadernos CEdes, Campinas, v. 20, n. 52, p. 104-121, nov. 2000. 
$\mathrm{M}$ aria Cristina Piumbato Innocentini $\mathrm{H}$ ayashi et al.

SO UZA, R.F. Inovação educacional no século xIx: a construção do currículo da escola primária no Brasil. Cadernos Cedes, Campinas, v. 20, n. 51, p. 9-28, nov. 2000.

SO U ZA, R.F. Tempos de infância, tempos de escola: a ordenação do tempo escolar no ensino público paulista (1892-1933). Educação \& Pesquisa, São Paulo, v. 25, n. 2, p. 127-143, jul./dez. 1999.

VIDAL, D.G.; FARIA FILH O , L.M . H istória da educação no Brasil: a constituição histórica do campo (1880-1970). Revista Brasileira de H is tória, São Paulo, v. 23, jul. 2003. 